\title{
Transanal Ileal Pouch-Anal Anastomosis for Ulcerative Colitis - A Retrospective Single-Center Study Regarding Anastomotic Leakage and Episodes of Pouchitis in the Long-Term
}

\section{Aina Lask ( $\nabla$ aina.lask@charite.de )}

Charité Universitätsmedizin Berlin: Charite Universitatsmedizin Berlin https://orcid.org/0000-00019395-4273

\section{Matthias Biebl}

Charite University Hospital Berlin: Charite Universitatsmedizin Berlin

\section{Luca Dittrich}

Charite University Hospital Berlin: Charite Universitatsmedizin Berlin

\section{Andreas Fischer}

Charite University Hospital Berlin: Charite Universitatsmedizin Berlin

\section{Andreas Adler}

Charite University Hospital Berlin: Charite Universitatsmedizin Berlin

\section{Frank Tacke}

Charite University Hospital Berlin: Charite Universitatsmedizin Berlin

\section{Felix Aigner}

Barmherzige Brüder Krankenhaus Graz

\section{Rosa Schmuck}

Charite University Hospital Berlin: Charite Universitatsmedizin Berlin

\section{Sascha Chopra}

Charite University Hospital Berlin: Charite Universitatsmedizin Berlin

\section{Michael Knoop}

Charite University Hospital Berlin: Charite Universitatsmedizin Berlin Johann Pratschke

Charite University Hospital Berlin: Charite Universitatsmedizin Berlin

\section{Safak Gül-Klein}

Charite University Hospital Berlin: Charite Universitatsmedizin Berlin

\section{Research Article}

Keywords: transanal ileal pouch-anal anastomosis, pouchitis, ulcerative colitis, anastomotic leakage 
Posted Date: July 7th, 2021

DOl: https://doi.org/10.21203/rs.3.rs-672700/v1

License: (c) (1) This work is licensed under a Creative Commons Attribution 4.0 International License. Read Full License 


\section{Abstract}

\section{Introduction:}

Colectomy with transanal ileal pouch-anal anastomosis (taIPAA) is a surgical technique that can be used to treat benign colorectal disease. Ulcerative colitis (UC) is the most frequent inflammatory bowel disease (IBD) and although pharmacological therapy has improved, colectomy rates reach up to $15 \%$. Objective of this study was to determine anastomotic leakage (AL) rates and treatment after taIPAA as well as shortand long-term pouch function.

\section{Patients and Methods:}

Data from a prospectively collected database of all patients undergoing talPAA in our center between March 2015 and August 2019 was analyzed retrospectively. Patients with indications other than UC or with adjuvant chemotherapy following colectomy for colorectal carcinoma were excluded.

\section{Results:}

Of 23 patients undergoing taIPAA in our center 20 patients met the inclusion criteria, with a median age of 36 years at the time of pouch formation. Overall prevalence of $A L$ was $10 \%$ with one early ( 11 days after operation) and one late AL (19 months after operation). In both patients pouches could be preserved with a multimodal approach based on endosponge therapy. Data on short-term pouch function could be obtained in 11 (55.8\%) patients and was satisfactory in all cases. In the long-term we observed a pouchitis rate of $57.9 \%$ and a pouch failure rate of $5.3 \%$.

\section{Conclusion:}

In our study, taIPAA surgery is a safe procedure and results in good patient outcome. The rate of AL is comparable to transabdominal IPAA. In order to fully evaluate the risks and benefits of talPAA further studies with larger cohorts of patients are required.

\section{Introduction}

Ulcerative colitis (UC) is the most common inflammatory bowel disease (IBD) and exceeds the incidence and prevalence of Crohn's disease in most countries around the world (1). Over the past few decades, pharmacologic therapy has improved, limiting the need for surgery to cases of refractory or steroiddependent disease, colorectal cancer or surgical emergencies such as toxic megacolon, perforation or lifethreatening haemorrhage (2). In the course of the disease, medical therapy refractory UC, requiring surgical treatment, leads to reconstructive surgery rates by restoring continuity of up to $15 \%$ (3). In this regard, the use of minimally invasive ileal pouch anal anastomosis (IPAA) is the favored technique $(4,5)$.

Transanal total mesorectal excision (TaTME) has first been established for sphincter-preserving rectal resection due to rectal carcinoma, providing better access and overview especially in obese patients or 
male individuals with naturally narrow pelvis $(6,7)$. Subsequently, transanal minimally invasive surgery (TAMIS) has also been implemented in operations for transanal IPAA (taIPAA) and, as already proven in various studies, also provides satisfactory surgical results and comparable complication rates to the pure transabdominal approach (8-10). Anastomotic leakage (AL) is a common complication in colorectal surgery with significant postoperative morbidity (11). In malignant as well as benign indications for surgery, AL results in chronic inflammation, fistulae or stenosis, reduced quality of life and eventually anastomotic failure with permanent stoma (11-13). Additionally, in colorectal carcinoma, AL is associated with reduced disease-free and overall survival $(14,15)$. Besides $A L$, pouchitis is the most frequent complication of IPAA significantly impairing pouch function and quality of life $(16,17)$. AL in association to pouch complications might be of relevant impact for pouch failure after $\operatorname{IPAA}(9,18)$.

The multimodal treatment procedures of AL management include - depending on the extent of AL antibiotic therapy, radiological or endoscopic interventions as well as reoperation with the intend to preserve continuity, as recently shown by different groups for AL for rectal cancer and inflammatory bowel disease (19-21).

Therefore, the aim of our retrospective study was to analyze patients after taIPAA for UC, regarding incidence and course of AL as well as episodes of pouchitis is and associated hospital readmissions, especially in the long-term.

\section{Patients And Methods}

\section{Patient characteristics and operative details}

All consecutive patients were analyzed retrospectively that had been subjected to a taIPAA in our department. All patients eligible for laparoscopic resection were offered the transanal approach. Those who chose taIPAA were prospectively recruited and gave written informed consent for the international LOREC $\circledast$ registry from December 2014 to January 2020. The study was performed in accordance with the Declaration of Helsinki and its amendments and an authorization has been granted by the Charité Instiutionals (Reg. No. 711/16). For clinical data such as sex, date of birth, preoperative data (therapy, BMI, extent of inflammation), operative data (operation time) and postoperative course as well as short and long-term follow-up data (complications after Clavien/Dindo; re-incurrences), patient data were collected anonymously.

From February 2015 to August 2019, talPAA, performed in the context of a two or three staged restorative proctocolectomy (RPC), was applied in 23 patients for benign colorectal disease at our Department of Surgery, Campus Virchow Klinikum and Campus Charité Mitte at Charité - Universitätsmedizin Berlin. For this analysis, we only considered taIPAA in patients with ulcerative colitis (UC) and hence excluded three patients. Of those, one suffered from familial adenomatosis polyposis (FAP), one from Crohn's disease and a third patient diagnosed with UC was excluded due to additional colorectal carcinoma with adjuvant chemotherapy after colectomy and therefore diverging postoperative care (Table 1 and Fig. 1). 
Relevant data (clinical course, laboratory chemical parameters, hospital stay, readmissions) for our patient cohort were analyzed retrospectively. Postoperative complications were defined according to Clavien/Dindo with a special focus on complications > II (Table 2).

Occurrence of early and late anastomotic leakage within the first 30 (eAL) and 31 to 90 (IAL) days or later was the primary endpoint. Secondary endpoints included pouch complications (pouchitis, fistula, stenosis). These endpoints were assessed and evaluated at regular follow-up. One patient did not receive ileostomy closure at our Department of surgery, hence data on short- and long-term follow up could not be obtained.

\section{Transanal lleal Pouch-Anal Anastomosis (taIPAA)}

The whole operation procedure for UC was performed either as a two or three staged procedure with an interval of 3-6 months between the operations. While the first operation comprised subtotal colectomy and terminal ileostomy, the second operation included ileal completion proctectomy and pouch-anal anastomosis with diverting loop-ileostomy. The last operation contained ileostomy closure. Before definitive ileostomy closure endoscopy of the pouch function was performed to exclude severe inflammation (pouchitis) or AL. lleostomy closure only took place in absence of inflammation and inconspicuous anastomosis region.

In one patient colectomy as well as pouch formation were performed at once due to an excellent remission of inflammation. One patient in our cohort did not undergo loop ileostomy due to severe adhesions. Basically, diverting loop ileostomy is standard at our institution, but may be considered optional in patients at very low risk for anastomotic leakage and/ or increased risk for complications. All operations for pouch formation were conducted in a hybrid technique including minimally invasive transabdominal approach and combined transanal approach.

\section{Data collection}

Data was collected in a prospective database for patients receiving taIPAA and analyzed retrospectively for perioperative complications and postoperative clinical course. For all patients the subsequent data were analyzed: demographics (age, gender), BMI, American society of Anaesthesiologists score (ASA), comorbidities, preoperative course of disease, operative details (Table 1), postoperative morbidity and mortality, complications with special focus on AL (time of diagnosis, treatment approach, treatment duration) (Table 2 and 3) short-term (first 60 days after ileostomy closure) (Table 4) and long-term (1 to 5 years after ileostomy closure) pouch function (Table 5), pouchitis (clinical symptoms, confirmed via endoscopy), fistula, stenosis and pouch failure (table 6).

\section{Statistical analysis}

Statistical analysis was performed using Microsoft Excel. In descriptive statistics continuous variables were reported as mean or median values with range. Categorical variables were quantified using frequencies and percentage. Follow-up period started at the day of last operation. 


\section{Results}

\section{Patient characteristics and operative details}

Gender distribution presented more male patients (male 65\%; female 35\%) with median age of 36 years at the time of taIPAA. The median time from first diagnosis of UC to subtotal colectomy was 36 months (1408 months). 18 patients (90\%) received a 3-step procedure as described earlier. One patient was operated in a 2-step procedure with colectomy and pouch-formation in the same operation. Another patient did not receive diverting loop-ileostomy due to multiple adhesions in the second step. Detailed information on patients' demographics and clinical features as well as on the operation are shown in Table 1. 
Table 1

Patient characteristics and operative details

\begin{tabular}{|ll}
\hline patients & $\mathbf{n = 2 0}$ \\
\hline Sex (male) & $13(65 \%)$ \\
\hline median age (years, range) & $36.1(14-72)$ \\
\hline mean BMI $\left(\mathrm{kg} / \mathrm{m}^{2}\right.$, range) & $23.3(17-32.8)$ \\
\hline ASA Score & $4(20 \%)$ \\
\hline I & $14(70 \%)$ \\
\hline II & $2(10 \%)$ \\
\hline III & \\
\hline pre-existing health conditions & 0 \\
\hline smoker & $2(10 \%)$ \\
\hline diabetes & $3(15 \%)$ \\
\hline previous abdominal operation & $36(1-408)$ \\
\hline median time from diagnosis of UC to operation (months, range) & $18(90 \%)$ \\
\hline Three staged procedure & $2(10 \%)$ \\
\hline Two staged procedure & $353(134-905)$ \\
\hline mean operation time talPAA (minutes, range) & $7(35 \%)$ \\
anastomosis & $13(65 \%)$ \\
\hline stapled & $1(0-3)$ \\
handsewn & \\
\hline cufflength (cm from dentate line, median and range) & \\
\hline BMI Bo & \\
\hline
\end{tabular}

$\mathrm{BMI}=$ Body Mass Index, ASA = American society of Anaesthesiologists, talPAA = transanal ileal pouch anal anastomosis,

\section{Anastomotic leakage and postoperative clinical course}

Complications according to Clavien/Dindo $>$ II took part over all three operation procedures, in total four patients (20\%). We observed one patient with severe complications for colectomy $(6.4 \%)$, two (10\%) for pouch formation and three (15.8\%) for ileostomy closure (Table 2 ). 
Table 2

Postoperative complications

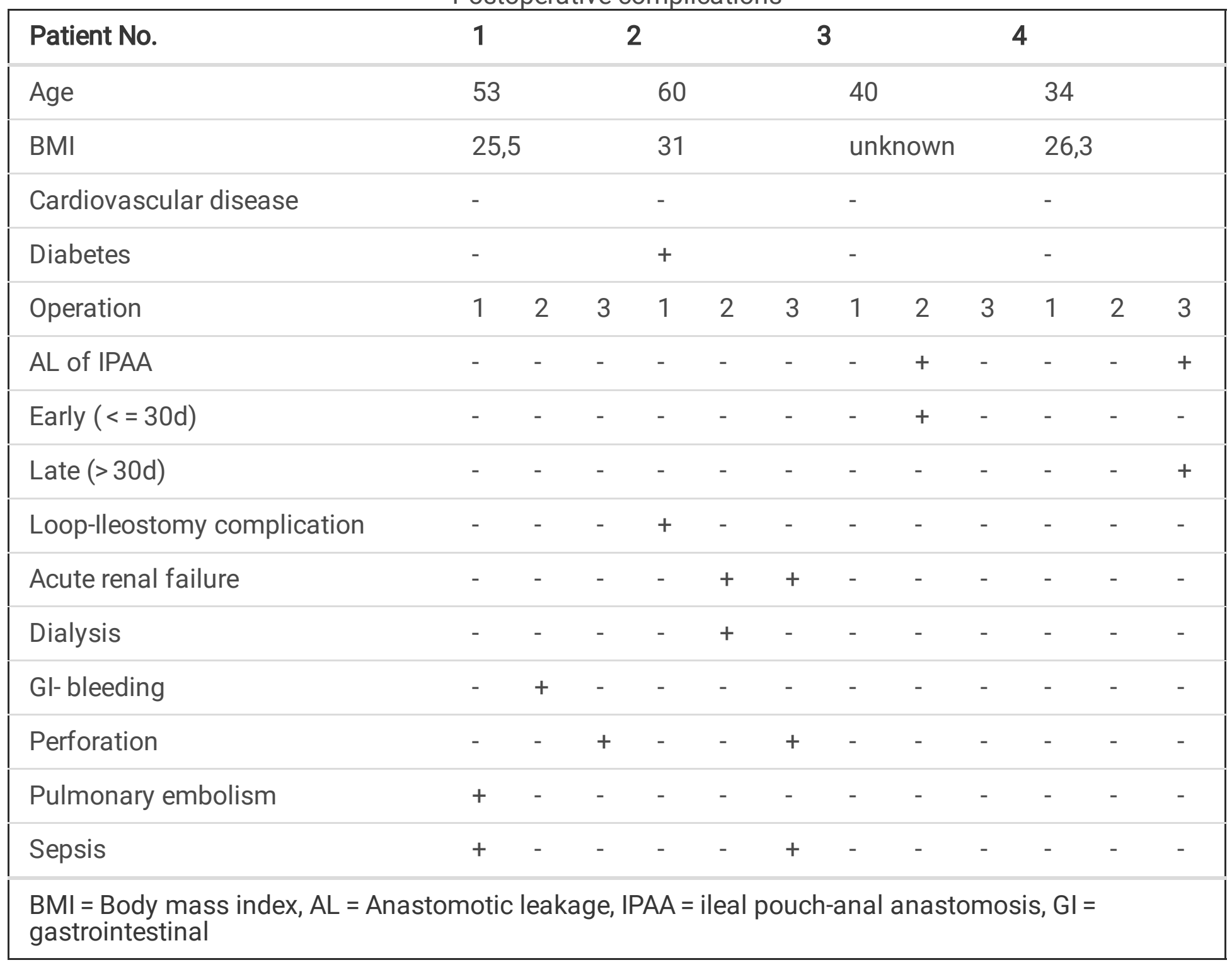

Two patients (10\%) of our cohort developed anastomotic leakage of ileal pouch-anal anastomosis. One patient was diagnosed with eAL on 13th postoperative day. The second patient showed IAL 19 months after diverting loop-ileostomy closure. Both patients were primarily treated with endosponge therapy and pouches could be preserved. The eAL required only one session of endosponge replacement, while IAL needed a multimodal approach including multiple endosponge changes.

The patient with IAL first received two cycles of endosponge therapy followed by a transanal suture completing the multimodal therapy procedure. Recurrence of AL 51 days after transanal suture was again treated with four times of endosponge therapy and re-operation for performing a diverting loop-ileostomy after the first cycle (Table 3). Definitive ileostomy closure could be achieved 380 days after last treatment for AL. 
Table 3

Anastomotic leakage and course of treatment

\begin{tabular}{|lll|}
\hline Patient No. & $\mathbf{3}$ & $\mathbf{4}$ \\
\hline Endo-SPONGE® therapy (frequency) & 1 & $2 / 4$ \\
\hline length of treatment (days) & 3 & $5 / 12$ \\
\hline transanal suture & - & Yes \\
\hline Reopening of ileostomy & - & Yes \\
\hline Preserved anastomosis & Yes & Yes \\
\hline AL related mortality & - & - \\
\hline AL = anastomotic leakage & & \\
\hline
\end{tabular}

\section{Pouch function in the short- and long-term}

Pouch function in the short-term was obtained for fourteen patients (73.7\%) (Table 4). None of the patients displayed any signs of pouchitis, fistula or stenosis. Pouch function was sufficient with no permanent incontinence occurring. Intermittent incontinence was documented in four (28.6\%) patients. Stool frequencies were reported for 11 patients, with one (6\%) patient at a frequency of 2-5 times per day, three $(27.3 \%)$ patients at 6-8 times per day and two (11.2\%) patients at 9-10 times per day. Five (45.5\%) patients recorded stool frequencies of 11-20 times per day. 
Table 4

Short-term pouch function (20-60 post

operation)

\begin{tabular}{|ll|}
\hline Patients & $\mathbf{n}=14$ \\
\hline Stool frequency $(\mathrm{n}=11)$ & \\
\hline $2-5$ & $1(9.1 \%)$ \\
\hline $6-8$ & $3(27.3 \%)$ \\
\hline $9-10$ & $2(18.2 \%)$ \\
\hline $10-20$ & $5(45.5 \%)$ \\
\hline$>20$ & 0 \\
\hline Incontinence & \\
\hline None & $10(71.4 \%)$ \\
\hline intermittent & $4(28.6 \%)$ \\
\hline permanent & 0 \\
\hline Pouchitis & 0 \\
\hline Fistula & 0 \\
\hline Stenosis & 0 \\
\hline Pouch failure & 0 \\
\hline
\end{tabular}

In the long-term follow-up, comprising 1 to 5 years, in total 11 (57.9\%) patients out of 19 patients developed pouchitis, at a mean of 475 days (91-1231 days) after ileostomy closure (Table 5). Six (54.4\%) patients were diagnosed within the first year after ileostomy closure.

Additionally three (27.3\%) patients developed fistula, all in direct coincidence to ileal-pouch-anal anastomosis. Out of those fistulas two were blind fistulas and one was a pouch-vaginal fistula with intermittent vaginal defecation. 
Table 5

Long-term pouch function

\begin{tabular}{|lllll|}
\hline & $\mathbf{1 - 2}$ years & $\mathbf{2 - 3}$ years & $\mathbf{3 - 4}$ years & $\mathbf{>}$ 4 years \\
\hline $\mathrm{n}$ & 11 & 12 & 5 & 6 \\
\hline AL & $1(9.1 \%)$ & $1(8.3 \%)$ & 0 & 0 \\
\hline Pouchitis & $5(45.5 \%)$ & $5(41.6 \%)$ & $2(40 \%)$ & 0 \\
\hline Fistula & $1(9.1 \%)$ & $3(25 \%)$ & $1(20 \%)$ & $1(16,6 \%)$ \\
\hline Stenosis & 0 & $1(8.3 \%)$ & 0 & 0 \\
\hline Pouch failure & $1(9.1 \%)$ & $1(8.3 \%)$ & $1(20 \%)$ & 0 \\
\hline AL = anastomotic leakage & & & \\
\hline
\end{tabular}

The eight remaining patients had no endoscopic signs of pouchitis, while one (12.5\%) presented a blind, asymptomatic fistula during routine postoperative endoscopy. One (9.1\%) patient with pouchitis presented additional stenosis of the ileal pouch-anal anastomosis and was treated six times via ambulatory endoscopic dilatation. In 8 (72.7\%) patients out of those 11 patients with pouchitis, a successful treatment was achieved by pharmacological therapy, comprising mainly antibiotics, topical and systemic steroids and in severe cases biologicals (table 6). Meanwhile only 3 (27.3\%) patients out of the pouchitis group still showed signs of pouchitis at last follow up. Here one patient was recommended for pouch removal and terminal ileostomy due to severe pouchitis with multiple fistulae resulting in a pouch failure rate of $5.3 \%$. Actually the patient is in regular internal and surgical control and declines pouch removal.

Table 6: Overview to pouchitis related characteristics 


\begin{tabular}{|c|c|c|c|c|c|c|c|c|c|c|c|}
\hline Patient No. & 1 & 5 & 6 & 8 & 11 & 12 & 13 & 14 & 16 & 18 & 20 \\
\hline Age & 34 & 39 & 30 & 41 & 35 & 48 & 33 & 33 & 17 & 36 & 59 \\
\hline BMI & 26.3 & 22.2 & 22 & 20.2 & 29.6 & 32.8 & 21.5 & 20.4 & 22.5 & 17 & 30.9 \\
\hline $\begin{array}{l}\text { Cardiovascular } \\
\text { disease }\end{array}$ & - & - & - & - & - & - & - & - & - & - & - \\
\hline Diabetes & - & - & - & - & - & - & - & - & - & - & - \\
\hline $\begin{array}{l}\text { First diagnosed } \\
\text { (days p.o.) }\end{array}$ & 586 & 1231 & 309 & 625 & 819 & 298 & 237 & 91 & 459 & 360 & 210 \\
\hline \multicolumn{12}{|l|}{$\begin{array}{l}\text { Extraintestinal } \\
\text { manifestation }\end{array}$} \\
\hline - Arthritis & Yes & - & - & - & - & Yes & - & - & - & - & - \\
\hline - Dermatitis & Yes & - & - & - & - & Yes & - & - & - & - & - \\
\hline - PSC & - & - & - & - & Yes & - & Yes & - & - & - & - \\
\hline - Other & - & - & - & - & - & - & - & Yes* & - & - & - \\
\hline Stenosis & - & - & - & - & - & - & - & - & - & - & Yes \\
\hline Fistula & Yes & - & - & - & - & Yes & - & - & - & - & Yes \\
\hline \multicolumn{12}{|l|}{ Treatment } \\
\hline - antibiotics & Yes & Yes & Yes & Yes & Yes & Yes & - & Yes & - & - & - \\
\hline - steroids (top.) & - & Yes & Yes & - & - & - & - & - & - & - & - \\
\hline - steroids (sys.) & - & - & Yes & - & - & - & - & - & - & - & - \\
\hline - 5-ASA (top.) & - & Yes & Yes & - & - & Yes & - & - & - & Yes & - \\
\hline - biologicals & - & - & Yes & - & - & Yes & Yes & - & Yes & - & - \\
\hline
\end{tabular}

\section{Discussion}

Transanal surgery has mainly been studied in TaTME as therapy for rectal carcinoma and provides comparable oncological outcomes, yet better pathologic resection status, shorter operation time, lower conversion rate and lower overall postoperative complication rate in comparison to laparoscopic TME $(12,22-26)$. Although the transanal approach for oncological surgery is well researched since first performed for TME in 2010 (7) and offers improved surgical access to the otherwise often challenging, narrow pelvis (6), it is still not as widely established for benign indications such as UC. Currently, taIPAA is 
reported to provide comparable functional results and postoperative morbidity and mortality to the transabdominal approach with shorter operation time and conversion rate, but still study populations are relatively small and randomized controlled trials have not been conducted so far $(8,9,27)$.

In our study we observed a complication rate (Clavien/Dindo > II) of $10 \%$ for pouch formation, which is comparable to results reported recently for transabdominal IPAA (17) and even slightly lower than in two studies concerning taIPAA $(8,9)$. Yet, these studies also showed higher complication rates for transabdominal IPAA resulting in no significant difference between both approaches. AL occurred in $10 \%$ of all patients in our study. These results are consistent with findings for IPAA before implementation of the transanal approach $(18,28)$, and similar AL rates have also been shown for talPAA $(8,9)$.

Chandrasinghe et al. even reported a trend for lower AL rates in taIPAA compared to transabdominal IPAA, which did not reach statistical significance (8) and could not be verified in our study. Course of treatment for AL after taIPAA has not yet been reported in detail.

In our study, only one eAL and one IAL was observed. Treatment was aimed at preserving the anastomosis founding on endosponge therapy. While eAL could be treated only with endosponge therapy, IAL required a multimodal approach consisting of endosponge therapy, transanal suture and reopening of diverting loop-ileostomy. Our therapeutic approach relies on our experiences after TaTME for rectal carcinoma, where we developed a differentiated therapy strategy for AL (20). Endosponge therapy for AL after IPAA has not yet been widely researched, but the few studies existing show non-inferiority in comparison to conventional treatment and high rates of pouch preservation $(21,29)$.

In our study, we did not observe any pouch failure due to $A L$ with an overall pouch failure rate of $5.3 \%$, which is also consistent with earlier findings $(8,17)$. The only detected patient with pouch failure had an underlying severe pouchitis which was therapy refractory to pharmalogical treatment and therefore recommended for pouch removal and terminal ileostomy.

Pouchitis is one of the most frequent complications after IPAA $(28,30)$ and associated with significant morbidity and reduced quality of life $(31,32)$. Pouchitis rates after IPAA reach up to $60 \%$ with increasing incidence during postoperative follow-up $(16,30,33)$ and may result in chronic pouch dysfunction and in severe cases pouch failure (34). The overall pouchitis rate was 11 (57.9\%), with half of the patients developing symptoms within one year after last operation. Nevertheless, pharmacological treatment was successful in $72.7 \%$ resulting in a good functional outcome in long-term follow-up. There are still only few studies on treatment for acute and chronic pouchitis leaving therapeutic strategies with highly variable outcomes and lacking sufficient scientific evidence $(35,36)$.

In order to improve therapy for pouchitis more research is needed. In the only study comparing long-term results of taIPAA and transabdominal IPAA, no significant difference was found neither between pouchitis rates nor health related quality of life including sexual function (8). Long-term follow-up for transabdominal IPAA shows over $90 \%$ of patients being satisfied with the operative result, despite minor complications such as nocturnal seepage or higher daily stool frequencies $(17,37,38)$. 
Our study is limited by its retrospective design without option to rule out potential bias and restricted number of patients included. However, the monocentric design of our study ensured that the same experienced colorectal surgeons' team has performed all procedures, resulting in excellent comparability of postoperative outcomes.

In summary of our study, taIPAA for UC was a safe procedure at a low overall postoperative complication rate and satisfactory short-term and long-term outcome. AL rates were comparable to transabdominal IPAA with high rates of anastomosis preservation. Since taIPAA has been introduced only a few years ago, studies for long-term outcomes and evaluation of larger patient cohorts are necessary to fully understand possible advantages or downsides of this surgical approach.

\section{Abbreviations}

\section{5-ASA}

5-aminosalicylic acid

$\mathrm{AL}$

anastomotic leakage

ASA

American society of Anaesthesiologists

$\mathrm{BMI}$

body mass index

eAL

early anastomotic leakage

FAP

familial adenomatosis polyposis

GI

gastrointestinal

IBD

inflammatory bowel disease

IAL

late anastomotic leakage

PSC

primary sclerosing cholangitis

RPC

restorative proctocolectomy

Sys.

systemic

talPAA

transanal ileal pouch-anal anastomosis

TaTME

transanal total mesorectal excision 
Top.

topical

UC

ulcerative colitis

\section{Declarations}

Ethics approval: An authorization for this study has been granted by the Charité Instiutionals (Reg. No. 711/16).

Consent for publication: All patients gave written informed consent for the international LOREC® registry

Availability of data and materials: The datasets used and/or analysed during the current study are available from the corresponding author on reasonable request

Competing interests: The authors declare that they have no competing interests

Funding: The authors have no funding to declare for this work.

Authors contribution: AL collected the data and wrote the paper. FA and MB performed the surgery and supervised and corrected the manuscript. LD collected the data. AF and AA helped with data acquisition. FT supervised conservative patient treatment and corrected the manuscript. RS, SC, MK and JP supervised the study and corrected the manuscript. SGK designed and performed the research and wrote and corrected the paper. All authors have made substantial contributions to the study, including conception and design, the acquisition, analysis and interpretation of data, drafting or critical revision of the paper. All authors read and approved the final manuscript.

\section{References}

1. Ng SC, Shi HY, Hamidi N, Underwood FE, Tang W, Benchimol El, et al. Worldwide incidence and prevalence of inflammatory bowel disease in the 21 st century: a systematic review of populationbased studies. Lancet. 2018;390(10114):2769-78. DOI:10.1016/S0140-6736(17)32448-0.

2. Kornbluth A, Sachar DB. Practice Parameters Committee of the American College of G. Ulcerative colitis practice guidelines in adults: American College Of Gastroenterology, Practice Parameters Committee. Am J Gastroenterol. 2010;105(3):501 - 23; quiz 24 DOI: 10.1038/ajg.2009.727.

3. Targownik LE, Singh H, Nugent Z, Bernstein CN. The epidemiology of colectomy in ulcerative colitis: results from a population-based cohort. Am J Gastroenterol. 2012;107(8):1228-35.

DOI:10.1038/ajg.2012.127.

4. Fleming FJ, Francone TD, Kim MJ, Gunzler D, Messing S, Monson JR. A laparoscopic approach does reduce short-term complications in patients undergoing ileal pouch-anal anastomosis. Dis Colon Rectum. 2011;54(2):176-82. DOI:10.1007/DCR.0b013e3181fb4232. 
5. Wu XJ, He XS, Zhou XY, Ke J, Lan P. The role of laparoscopic surgery for ulcerative colitis: systematic review with meta-analysis. Int J Colorectal Dis. 2010;25(8):949-57. DOI:10.1007/s00384-010-08985.

6. Atallah S, Martin-Perez B, Albert M, deBeche-Adams T, Nassif G, Hunter L, et al. Transanal minimally invasive surgery for total mesorectal excision (TAMIS-TME): results and experience with the first 20 patients undergoing curative-intent rectal cancer surgery at a single institution. Tech Coloproctol. 2014;18(5):473-80. DOI:10.1007/s10151-013-1095-7.

7. Sylla P, Rattner DW, Delgado S, Lacy AM. NOTES transanal rectal cancer resection using transanal endoscopic microsurgery and laparoscopic assistance. Surg Endosc. 2010;24(5):1205-10. DOI:10.1007/s00464-010-0965-6.

8. Chandrasinghe P, Carvello M, Wasmann K, Foppa C, Tanis P, Perry-Woodford Z, et al. Transanal Ileal Pouch-Anal Anastomosis for Ulcerative Colitis has Comparable Long-Term Functional Outcomes to Transabdominal Approach: A Multicentre Comparative Study. J Crohns Colitis. 2020;14(6):726-33. DOI:10.1093/ecco-jcc/jjz174.

9. de Buck van Overstraeten A, Mark-Christensen A, Wasmann KA, Bastiaenen VP, Buskens CJ, Wolthuis AM, et al. Transanal Versus Transabdominal Minimally Invasive (Completion) Proctectomy With Ileal Pouch-anal Anastomosis in Ulcerative Colitis: A Comparative Study. Ann Surg. 2017;266(5):878-83. DOI:10.1097/SLA.0000000000002395.

10. Capolupo GT, Carannante F, Masciana G, Lauricella S, Mazzotta E, Caricato M. Transanal proctocolectomy and ileal pouch-anal anastomosis (TaIPAA) for ulcerative colitis: medium term functional outcomes in a single centre. BMC Surg. 2021;21(1):17. DOI:10.1186/s12893-020-01007-z.

11. Boccola MA, Buettner PG, Rozen WM, Siu SK, Stevenson AR, Stitz R, et al. Risk factors and outcomes for anastomotic leakage in colorectal surgery: a single-institution analysis of 1576 patients. World $\mathrm{J}$ Surg. 2011;35(1):186-95. DOI:10.1007/s00268-010-0831-7.

12. Penna M, Hompes R, Arnold S, Wynn G, Austin R, Warusavitarne J, et al. Incidence and Risk Factors for Anastomotic Failure in 1594 Patients Treated by Transanal Total Mesorectal Excision: Results From the International TaTME Registry. Ann Surg. 2019;269(4):700-11.

DOI:10.1097/SLA.0000000000002653.

13. Nesbakken A, Nygaard K, Lunde OC. Outcome and late functional results after anastomotic leakage following mesorectal excision for rectal cancer. Br J Surg. 2001;88(3):400-4. DOI:10.1046/j.13652168.2001.01719.x.

14. Mirnezami A, Mirnezami R, Chandrakumaran K, Sasapu K, Sagar P, Finan P. Increased local recurrence and reduced survival from colorectal cancer following anastomotic leak: systematic review and meta-analysis. Ann Surg. 2011;253(5):890-9. DOI:10.1097/SLA.0b013e3182128929.

15. Khoury W, Lavery IC, Kiran RP. Impact of early reoperation after resection for colorectal cancer on long-term oncological outcomes. Colorectal Dis. 2012;14(3):e117-23. DOI:10.1111/j.14631318.2011.02804.x. 
16. Barnes EL, Herfarth HH, Kappelman MD, Zhang X, Lightner A, Long MD, et al. Incidence, Risk Factors, and Outcomes of Pouchitis and Pouch-Related Complications in Patients With Ulcerative Colitis. Clin Gastroenterol Hepatol. 2020. DOI:10.1016/j.cgh.2020.06.035.

17. Carcamo L, Miranda P, Zuniga A, Alexander E, Molina ME, Urrejola G, et al. lleal pouch-anal anastomosis in ulcerative colitis: outcomes, functional results, and quality of life in patients with more than 10-year follow-up. Int J Colorectal Dis. 2020;35(4):747-53. DOI:10.1007/s00384-02003529-7.

18. Sahami S, Bartels SA, D'Hoore A, Fadok TY, Tanis PJ, Lindeboom R, et al. A Multicentre Evaluation of Risk Factors for Anastomotic Leakage After Restorative Proctocolectomy with lleal Pouch-Anal Anastomosis for Inflammatory Bowel Disease. J Crohns Colitis. 2016;10(7):773-8. DOI:10.1093/ecco-jcc/jjv170.

19. Boyce SA, Harris C, Stevenson A, Lumley J, Clark D. Management of Low Colorectal Anastomotic Leakage in the Laparoscopic Era: More Than a Decade of Experience. Dis Colon Rectum. 2017;60(8):807-14. DOI:10.1097/DCR.0000000000000822.

20. Guel-Klein S, Biebl M, Knoll B, Dittrich L, Weiss S, Pratschke J, et al. Anastomotic leak after transanal total mesorectal excision: grading of severity and management aimed at preservation of the anastomosis. Colorectal Dis. 2019;21(8):894-902. DOI:10.1111/codi.14635.

21. Wasmann KA, Reijntjes MA, Stellingwerf ME, Ponsioen CY, Buskens CJ, Hompes R, et al. Endo-sponge Assisted Early Surgical Closure of Ileal Pouch-anal Anastomotic Leakage Preserves Long-term Function: A Cohort Study. J Crohns Colitis. 2019;13(12):1537-45. DOI:10.1093/ecco-jcc/jjz093.

22. Ma B, Gao P, Song Y, Zhang C, Zhang C, Wang L, et al. Transanal total mesorectal excision (taTME) for rectal cancer: a systematic review and meta-analysis of oncological and perioperative outcomes compared with laparoscopic total mesorectal excision. BMC Cancer. 2016;16:380.

DOI:10.1186/s12885-016-2428-5.

23. Chang TC, Kiu KT. Transanal Total Mesorectal Excision in Lower Rectal Cancer: Comparison of ShortTerm Outcomes with Conventional Laparoscopic Total Mesorectal Excision. J Laparoendosc Adv Surg Tech A. 2018;28(4):365-9. DOI:10.1089/lap.2017.0520.

24. Burke JP, Martin-Perez B, Khan A, Nassif G, de Beche-Adams T, Larach SW, et al. Transanal total mesorectal excision for rectal cancer: early outcomes in 50 consecutive patients. Colorectal Dis. 2016;18(6):570-7. DOI:10.1111/codi.13263.

25. Lacy AM, Tasende MM, Delgado S, Fernandez-Hevia M, Jimenez M, De Lacy B, et al. Transanal Total Mesorectal Excision for Rectal Cancer: Outcomes after 140 Patients. J Am Coll Surg. 2015;221(2):415-23. DOI:10.1016/j.jamcollsurg.2015.03.046.

26. Dittrich L, Biebl M, Schmuck R, Gul S, Weiss S, Haase O, et al. Initial Experience with the Safe Implementation of Transanal Total Mesorectal Excision (TaTME) as a Standardized Procedure for Low Rectal Cancer. J Clin Med. 2020;10(1) DOI:10.3390/jcm10010072.

27. de Lacy FB, Keller DS, Martin-Perez B, Emile SH, Chand M, Spinelli A, et al. The current state of the transanal approach to the ileal pouch-anal anastomosis. Surg Endosc. 2019;33(5):1368-75. 
DOI:10.1007/s00464-019-06674-5.

28. Hueting WE, Buskens E, van der Tweel I, Gooszen HG, van Laarhoven CJ. Results and complications after ileal pouch anal anastomosis: a meta-analysis of 43 observational studies comprising 9,317 patients. Dig Surg. 2005;22(1-2):69-79. DOI:10.1159/000085356.

29. Rottoli M, Di Simone MP, Vallicelli C, Vittori L, Liguori G, Boschi L, et al. Endoluminal vacuum-assisted therapy as treatment for anastomotic leak after ileal pouch-anal anastomosis: a pilot study. Tech Coloproctol. 2018;22(3):223-9. DOI:10.1007/s10151-018-1762-9.

30. Simchuk EJ, Thirlby RC. Risk factors and true incidence of pouchitis in patients after ileal pouch-anal anastomoses. World J Surg. 2000;24(7):851-6. DOI:10.1007/s002680010136.

31. Turina M, Pennington CJ, Kimberling J, Stromberg AJ, Petras RE, Galandiuk S. Chronic pouchitis after ileal pouch-anal anastomosis for ulcerative colitis: effect on quality of life. J Gastrointest Surg. 2006;10(4):600-6. DOI:10.1016/j.gassur.2005.08.013.

32. Barnes EL, Herfarth HH, Sandler RS, Chen W, Jaeger E, Nguyen VM, et al. Pouch-Related Symptoms and Quality of Life in Patients with lleal Pouch-Anal Anastomosis. Inflamm Bowel Dis. 2017;23(7):1218-24. DOI:10.1097/MIB.0000000000001119.

33. Peyrin-Biroulet L, Germain A, Patel AS, Lindsay JO. Systematic review: outcomes and post-operative complications following colectomy for ulcerative colitis. Aliment Pharmacol Ther. 2016;44(8):80716. DOI:10.1111/apt.13763.

34. Fazio VW, Kiran RP, Remzi FH, Coffey JC, Heneghan HM, Kirat HT, et al. lleal pouch anal anastomosis: analysis of outcome and quality of life in 3707 patients. Ann Surg. 2013;257(4):679-85.

DOI:10.1097/SLA.0b013e31827d99a2.

35. Nguyen N, Zhang B, Holubar SD, Pardi DS, Singh S. Treatment and prevention of pouchitis after ileal pouch-anal anastomosis for chronic ulcerative colitis. Cochrane Database Syst Rev. 2019;11:CD001176. DOI:10.1002/14651858.CD001176.pub5.

36. Suzuki H, Ogawa H, Shibata C, Haneda S, Watanabe K, Takahashi K, et al. The long-term clinical course of pouchitis after total proctocolectomy and IPAA for ulcerative colitis. Dis Colon Rectum. 2012;55(3):330-6. DOI:10.1097/DCR.0b013e3182417358.

37. Hahnloser D, Pemberton JH, Wolff BG, Larson DR, Crownhart BS, Dozois RR. Results at up to 20 years after ileal pouch-anal anastomosis for chronic ulcerative colitis. Br J Surg. 2007;94(3):333-40. DOI:10.1002/bjs.5464.

38. McIntyre PB, Pemberton JH, Wolff BG, Beart RW, Dozois RR. Comparing functional results one year and ten years after ileal pouch-anal anastomosis for chronic ulcerative colitis. Dis Colon Rectum. 1994;37(4):303-7. DOI:10.1007/BF02053588.

\section{Figures}




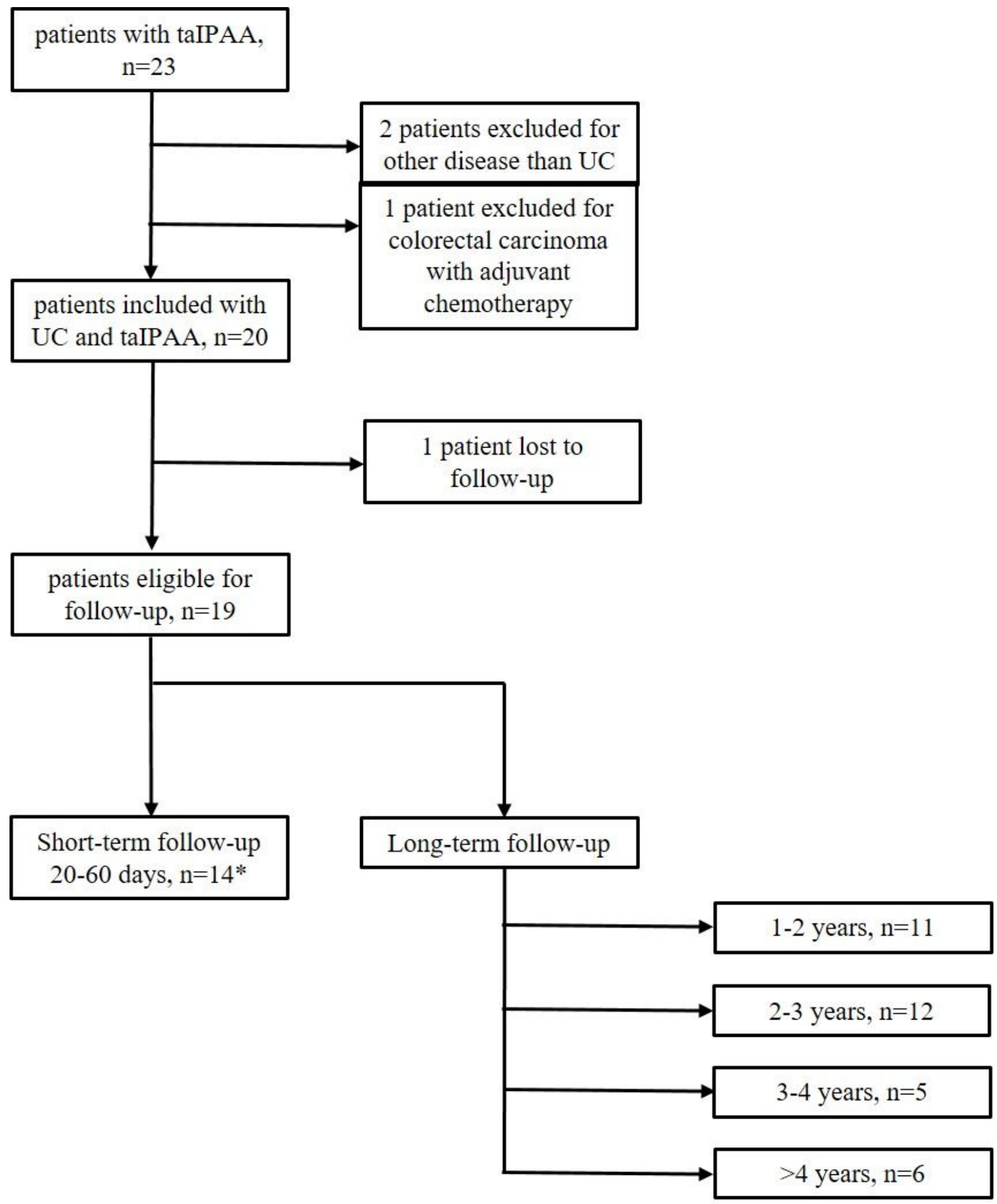

\section{Figure 1}

Patient cohort, * Five patients rejcted routine postoperative follow up at our department of surgery within 20 to 60 days due to good clinical status in ambulatory control 